\title{
Planning of sustainable agricultural groundwater development in canal areas
}

\author{
D. Kashyap ${ }^{1} \&$ S. Ghosh ${ }^{2}$ \\ ${ }^{1}$ IIT Roorkee, India \\ ${ }^{2} C E S$, India
}

\begin{abstract}
Groundwater development in canal areas, apart from providing subsurface drainage, helps in enhancing the crop areas since the canal supplies are rarely adequate to meet the complete irrigation demands. Sustainability of this crop area enhancement and the associated groundwater development is linked to the requirement of restricting the resulting state variables viz. long-term water table depths and the stream-aquifer interflows within prescribed limits. In the present study, a simulation model is proposed to address this planning problem. The model accepts the crop areas and several other features of the hydro-agronomic system as inputs and computes the maximum water table depth and the streamaquifer interflows at critical times at the dynamic equilibrium. Under the dynamic equilibrium the excess of annual withdrawals over the annual vertical recharge is compensated by lateral inflows from hydraulically connected drains. As such the total annual inflow and outflow balance each other and the annual time series of head becomes stationary. Therefore dynamic equilibrium represents the annual scenario corresponding to an indefinite sustenance of the cropping/pumping pattern. The proposed strategy is illustrated by applying it to the command of Eastern Yamuna canal system (India) that is experiencing a severe water deficit. Simulation runs are conducted for three cropping patterns representing current scenario, ambitious and conservative patterns.
\end{abstract}

Keywords: groundwater, irrigation, sustainable.

\section{Introduction}

The present study addresses the problem of planning the cropping pattern and the associated groundwater withdrawals in agricultural areas wherein the irrigation 
requirements are met through groundwater development exclusively or through given canal supplies supplemented by the groundwater development. The envisaged planning accommodates the most rampant concerns in respect of groundwater development viz. excessive water table depth and the streamaquifer interflows. Thus, the objective of the planning is to arrive at a most rewarding cropping pattern that leads to sustainable water table depths as well as the stream aquifer interflows. This apparently requires linkage of a usually physically based groundwater model (simulator) to an optimizer (Bredehoeft and Young [1], Yu and Haimes [2], Kashyap and Chandra [3] etc.). However, this approach usually requires large computational effort (Gorelick [4]) since a physically based simulator is usually computationally expensive, and it may be called innumerable times during an optimization. This problem may be overcome by invoking approximate but computationally inexpensive simulators employing Kernel/ANN algorithms (Maddock [5, 6], Dreizin and Haimes [7], Ghosh and Kashyap [8, 9]).

Alternatively, the simulator may be run several times on trial cropping patterns to arrive at a feasible cropping pattern honouring all the constraints. In the present study, such a planning model is proposed and illustrated on a selected study area falling within rivers Yamuna and Hindon. The area comprises fertile agricultural land and is inhabited by energetic, progressive and prosperous farmers. Further, it comprises a good alluvial aquifer system with quite favorable characteristics and dependable recharge. The area is served by the Eastern Yamuna canal system that emanates from river Yamuna at Tajewala. In spite of such apparent abundance of canal and groundwater, the area has been experiencing a sustained decline of its water table. As such studies (CBIP [10], Rathi [11]) have been conducted in past to study the groundwater system of the area. The present study draws heavily from these preceding studies in terms of the basic data and a calibrated groundwater flow model. The available calibrated model of groundwater flow essentially simulates the head field at advancing times for a given forcing function comprising spatially and temporally distributed withdrawals and recharge. The model has been enhanced to make it compatible with the objectives of the present study by linking the forcing function to the cropping pattern. Further, the selected state variables of planning are derived from the basic model output viz. the head fields at advancing times. The details of the selected study area, available groundwater flow model and the model enhancement are discussed in the following paragraphs.

\section{Study area}

The study area (0.6 million hectares), elongated along the north-south direction, lies between latitude $29^{\circ} 18^{\prime}$ to $30^{\circ} 25^{\prime} \mathrm{N}$ and longitude $77^{\circ} 1^{\prime} 30^{\prime \prime}$ to $77^{\circ} 40^{\prime} 45^{\prime \prime} \mathrm{E}$. While, its longer dimension from north to south is $1965 \mathrm{~km}$, it extends by $70 \mathrm{~km}$ from west to east. It is bounded by rivers Yamuna and Hindon on the west and east side respectively. The two river boundaries merge towards the southern end. The area on the northern side interfaces with the Shiwalik mountainous formation. The available canal supplies in the study area are not sufficient to 
meet the irrigation water requirements. As such, there is a substantial ground water development in the area, and the pumped ground water is predominantly used for irrigation. The whole of the Yamuna-Hindon interbasin is part of vast Indo-gangetic alluvial plain which is almost a level country with gentle slope towards south east. The aquifer is predominantly alluvial and unconfined extending vertically up to about a depth of $90 \mathrm{~m}$ below ground. The area has a well established monsoon rainfall system characterized by heavy rainfall during the monsoon period viz. June to September.

\section{Available groundwater flow model}

A comprehensive groundwater flow model for the study area was developed by CBIP [10] and subsequently reviewed and fine tuned by Rathi [11]. The development included estimation of the aquifer and recharge parameters by an optimization algorithm. This model is adopted in present study to develop the planning model. It is essentially based upon a numerical solution of the following differential equation governing two-dimensional groundwater flow in a heterogeneous, anisotropic confined aquifer for unsteady state.

$$
\frac{\partial}{\partial x}\left(T_{x x} \frac{\partial h}{\partial x}\right)+\frac{\partial}{\partial y}\left(T_{y y} \frac{\partial h}{\partial y}\right)+W(x, y, t)=S_{y}(x, y) \frac{\partial h}{\partial t}
$$

where, $x, y=$ Cartesian coordinates in the directions of principal permeability, $t=$ time; $T_{x x}$ and $T_{y y}$ (both varying with $x$ and $y$ ) are the transmissivities in $x$ and $y$ direction deemed to be time-invariant, $S_{y}(x, y)$ is the storage coefficient/specific yield, $h(x, y, t)$ is the water table elevation, and $W(x, y, t)=$ net vertical abstraction. This confined flow equation has been invoked for studying an unconfined aquifer apparently because of large saturated thickness of the aquifer. The components of $\mathrm{W}$ are as follows:

$$
\mathrm{W}=\mathrm{GW}+\mathrm{E}-\left(\mathrm{R}_{\mathrm{r}}+\mathrm{R}_{\mathrm{i}}+\mathrm{R}_{\mathrm{S}}\right)
$$

where, $G W=$ groundwater withdrawal. $E=$ evapotranspiration, $R_{r}=$ rainfall recharge, $R_{i}=$ recharge from applied irrigation, $R_{S}=$ recharge from canal seepage. The governing differential equation is solved numerically by the finite difference method. The study area is discretized by 713 nodes falling at the intersection of 71 rows and 24 columns located at a spacing of $3.2 \mathrm{~km}$. Time is discretized adopting a time step of half month.

\subsection{Model parameters}

The adopted groundwater flow model comprises the usual aquifer parameters viz. transmissivity and storage coefficient/specific yield. The components of recharge from rainfall and applied irrigation appearing in the sink term (Equation (2)) are quantified by devising additional model parameters as follows. 
i) Rainfall recharge coefficient $(\alpha)$ : This parameter relates the unknown rainfall recharge $\left(R_{r}\right)$ to the known rainfall depth $(P)$ as follows:

$$
R_{r}=\alpha P
$$

ii) Canal seepage factor $(\beta)$ : This parameter relates the unknown canal seepage $\left(R_{S}\right)$ to the known canal water $\operatorname{supply}(Q)$ as follows:

$$
R_{S}=\beta Q
$$

Further, a major part of this canal seepage occurs along the main canals. The remaining part occurring through branches, distributaries, water courses etc may be well distributed over the entire area. As such, the recharge from canal seepage $\left(R_{S}\right)$ is considered as comprising two components viz. $R_{S l}$ : occurring along the main canal and $R_{S 2}$ : uniformly distributed over the entire area. The break-up is parameterized (in terms of a parameter $\xi$ ) as follows:

$$
\begin{gathered}
R_{S 1}=\xi \times R_{S} \\
R_{S 2}=(1-\xi) \times R_{S}
\end{gathered}
$$

iii) Applied irrigation recharge parameters $(F)$ : Recharge from the irrigation (emanating from canal water and groundwater) applied on the field is related to the corresponding application depths. Recalling that a fraction $\beta$ of the canal water is conceptualized as the seepage loss, the canal water available on the field is $(1-\beta) Q$. As such the recharge from the applied irrigation $\left(R_{i}\right)$ is related to the available canal water $[(1-\beta) Q]$ and the groundwater $(G W)$ as per the following parameterization:

$$
\begin{aligned}
R_{i} & =[Q(1-\beta)+G W] F \\
& =I_{r} \times F
\end{aligned}
$$

where, $I_{r}=$ Total applied irrigation and $F=$ applied irrigation recharge parameters termed as irrigation application efficiency. In the present study the parameter $F$ is considered as crop dependent. The crops are divided in two categories viz. paddy (rice) and non-paddy. Since, the paddy crop usually requires surface ponding, the recharge fraction $(F)$ is higher. As such, the factor $F$ is assigned as 0.5 for paddy and 0.30 for other crops.

iv) Critical depth to water table $(D T H)$ : The abstraction of water from the saturated zone in the form of evapotranspiration is assumed to be at potential rate when depth to water table falls below a critical depth $(D T H)$.

\subsection{Parameter estimation}

While calibrating the model, the parameter $\beta$ and $F$ are treated as known (Table 1) - essentially derived from the prevalent norms/practices. The other parameters are estimated by a minimization of sum of squares of difference between the observed/interpolated and model computed water table elevations.

The calibrated transmissivity varies from $1500 \mathrm{~m}^{2} /$ day to $1100 \mathrm{~m}^{2} /$ day from north towards south. The storage parameter $\left(S_{y}\right)$ was found be almost space invariant. The calibrated/adopted values of the parameters are given in Table 1. 
Table 1: $\quad$ Model and recharge parameter.

\begin{tabular}{|c|c|c|c|c|c|c|}
\hline \multirow{2}{*}{$S_{y}$} & \multirow{2}{*}{$A$} & \multirow{2}{*}{$B$} & $\xi$ & \multicolumn{2}{|c|}{$F$} & \multirow{2}{*}{ DTH(m) } \\
\cline { 5 - 6 } & & & & Paddy $\left(F_{1}\right)$ & Other crops $\left(F_{2}\right)$ & \\
\hline 0.22 & 0.33 & 0.385 & 0.20 & 0.50 & 0.30 & 2 \\
\hline
\end{tabular}

\section{Enhancement of groundwater flow model}

The available model described above is enhanced in several ways to facilitate the development of the envisaged groundwater planning model. The details are given in the following paragraphs.

\subsection{Incorporation of cropping pattern}

The available groundwater flow model provides the head field at the advancing times at 15 days' interval, for an assigned forcing function $(W)$ that is derived parametrically from data of rainfall, canal supplies and groundwater withdrawal $(G W)$. This parameterization is enhanced to link the $G W$ component to the cropping pattern by deriving the necessary groundwater pumpage for given cropping and canal availability patterns. The cropping pattern is defined in terms of areas under feasible crops in pre-stipulated zones of uniform cropping pattern. Thus, the agricultural component of $G W$ (Equation 2) term at any finite difference node (say $i^{\text {th }}$ node lying in $\ell^{\text {th }}$ zone) during any period (say $k^{\text {th }}$ ) is viewed as the total irrigation water requirement $\left(\sum_{j} a_{j l} \delta c_{j k}\right)$ minus the canal water availability $[(1-\beta) Q]$. This lead to the following expression for $G W_{i k}$ :

$$
G W_{i k}=\left[\sum_{j} a_{j l} \delta c_{j k}-(1-\beta) Q_{i k}\right]+G W_{i k}^{*}
$$

where, $G W_{i k}=$ groundwater withdrawal at $i^{\text {th }}$ node in $k^{\text {th }}$ time period, $G W_{i k}{ }^{*}=$ groundwater withdrawal for non-agricultural usage at $i^{\text {th }}$ node in $k^{\text {th }}$ time period, $\mathrm{a}_{j l}=$ fractional area under $j^{\text {th }}$ crop in $l^{\text {th }}$ zone, $\delta c_{j k}=$ unit irrigation water requirement of $j^{\text {th }}$ crop in $k^{\text {th }}$ period, $Q_{i k}=$ canal water released toward at $i^{\text {th }}$ node during $k^{\text {th }}$ period. The corresponding sink term $W_{i k}$ (representing the algebraic sum of all abstractions and fluxes) can be written as follows:

$$
W_{i k}=G W_{i k}-\left[\alpha P_{i k}+(1-\xi) \beta Q_{i k}+\left(I_{r} \times F\right]+\mathrm{E}\right.
$$

\subsection{Dynamic equilibrium}

An important issue concerning the envisaged planning is its time-frame. The irrigation demand and canal water supply usually vary with time, and on an 
average may be considered as periodic functions of time with a time period of one year. Noting that the irrigation demand is jointly met through groundwater and canal water, groundwater withdrawal for a given cropping pattern may also be deemed to follow an annual cycle. Nevertheless there may be some year to year variation around average cycles. In the deterministic approach these variations are ignored and compensated by enhancing the limits on the state variables appropriately. Thus, long term sustenance of a cropping pattern would require implementation of the corresponding annual pumping pattern over the years. Further, other components of "the forcing function" (like recharge from rainfall, canal seepage, irrigation etc.), and the boundary heads (say the river stage) may also be deemed to follow annual cycles.

Long term sustenance of annual cycles of the forcing function $(W)$ and of the boundary heads may over the time lead to state of dynamic equilibrium wherein the inflowing and outflowing volumes over a year balance each other and hence the corresponding groundwater storage change vanishes. The establishment of dynamic equilibrium would however require a boundary with a feedback mechanism that is a boundary which tends to stabilize the water table by increasing the recharge when the water table falls and vice versa. A river boundary wherein the river stage can be assumed to be practically unaffected by the stream-aquifer interflow satisfies this requirement.

The dynamic equilibrium would be characterized by head fields at the selected discrete times in a year, and year-long time series of the relevant state variables. Once the dynamic equilibrium is reached, this conglomerate of head fields and the time series of the state variables would repeat themselves over the years as the pumpage is sustained. State variable of interest (say the maximum depth to water table and the stream-aquifer interflows) under dynamic equilibrium would reflect the ultimate impact of the raising the envisaged cropping pattern and would be reached as the cropping pattern is sustained over the time indefinitely. Thus, restricting the chosen state variables under the dynamic equilibrium to acceptable limits may be considered as a planning for the sustainable cropping pattern/pumping patterns. This concept of sustainable development has been adopted in the planning models proposed herein. As such, the envisaged state variables are deemed to corresponding to the dynamic equilibrium.

\subsection{State variables}

The two envisaged state variables are the maximum depth to water table $(D)$ and the stream-aquifer interflow at a few selected critical times - both under dynamic equilibrium. The first step towards computation of these state variables for a given cropping pattern is to derive the head fields under dynamic equilibrium. This is accomplished by running the simulation model over the years until the following condition is satisfied.

When

$$
\begin{gathered}
\underset{i, k}{\operatorname{Max}}\left|h_{i k}^{(y)}-h_{i k}^{(y-1)}\right|<\varepsilon \\
\mathrm{i} \in \mathrm{I} \text { and } \mathrm{k} \in \mathrm{K}
\end{gathered}
$$


where, $h_{i k}^{(y)}=$ computed head at $i^{\text {th }}$ node at $k^{\text {th }}$ discrete time during $y^{\text {th }}$ year, $\varepsilon=$ the desired convergence factor, $I=$ set of nodes discretizing the area, and $K=$ set of times discretizing one year. Once this condition is satisfied, the head field $\left(h^{*}{ }_{i k}\right)$ at the dynamic equilibrium is defined as follows:

$$
h_{i k}^{*}=h_{i k}^{(y)}
$$

where $h_{i k}^{*}=$ head at $i^{\text {th }}$ node at $k^{\text {th }}$ discrete time at dynamic equilibrium. The state variable $D$ (the maximum water table depth at dynamic equilibrium) is derived from this head field as follows.

$$
\begin{gathered}
d_{i k}=G_{i}-h_{i k}^{*} \\
D=\underset{i, k}{\operatorname{Max}}\left(d_{i k}\right)
\end{gathered}
$$

where, $\mathrm{d}_{\mathrm{ik}}=$ water table depth at $i^{\text {th }}$ node at $k^{\text {th }}$ discrete time at dynamic equilibrium, $G_{i}=$ the ground elevation at $i^{\text {th }}$ node. Further the integrated streamaquifer interflow rate at the stipulated critical time (say $c$ ) is derived from the simulated head field $\left(h_{i c}^{*}\right)$ by applying Darcy's law across the stream-aquifer links.

\subsection{Output from the enhanced simulation model}

The enhanced simulation model presented in the preceding paragraphs is capable of simulating the envisaged state variables under dynamic equilibrium. The model input comprises the zone-wise cropping pattern $\left(a_{j \ell}\right)$ and several other features termed collectively herein as the hydro-agronomic system. This system may include a physiographic subsystem consisting of topographical levels across the study area, number of zones of uniform cropping pattern and their details like location, geographical area, cultivable area etc.; an aquifer sub-system consisting of aquifer parameters, boundary conditions, parameters of recharge from irrigation, canal seepage, rainfall etc., nodal groundwater withdrawals during different time periods for non-agricultural (say drinking water/ industrial) usage; a canal subsystem consisting of canal water availability at various nodes during different periods of a year; an agronomic subsystem consisting of the feasible crops in the study area their growing periods and water demands during different periods of a year etc. discussed earlier like canal water availability, feasible crops and their water demands, evaporation, rainfall, aquifer/recharge parameters, topographical elevations, boundary conditions etc.

\section{Simulation runs on enhancement model}

The enhanced simulation model described in the preceding paragraphs is applied to the Yamuna-Hindon interbasin, to compute the envisaged state variables for three selected cropping patterns. As discussed earlier, stream-aquifer interflows at critical times form a part of state variable vector under dynamic equilibrium. In the present application, the stream-aquifer interflow vector $\left(\boldsymbol{Q}_{c}\right)$ comprises 
four components viz. lateral recharge from Yamuna and Hindon at pre monsoon (viz. May end) and post monsoon (September end) times. These components are termed respectively as $q_{\text {pre }}^{Y}, q_{\text {post }}^{Y}, q_{\text {pre }}^{H}, q_{\text {post }}^{H}$. The components of the hydroagronomic system are derived from the available data comprising among others, spatial distribution of average month wise rainfall, spatial distribution of month wise canal water availability in the stipulated zones, month wise irrigation requirements for the stipulated crops, topographical elevations, aquifer/ recharge parameters, and boundary conditions.

Dirichlet type of boundary condition is assigned at the nodes of eastern and western boundaries. Northern boundary is assumed to be impervious. Although, the model run requires an initial condition (comprising the head field at the beginning of the simulation), the chosen state variables (viz. the maximum depth to water table and the four stream aquifer interflow rates-all at the dynamic equilibrium) are independent of it.

In the present study area, there are two major crop seasons viz. Kharif (June to September) and Rabi (October to May). While in Kharif season the major crop is paddy, wheat is the dominant crop in Rabi season. Other minor crops in the two seasons are termed as other Kharif and other Rabi respectively. Further, the sugarcane crop is perennial. As such, five crops considered for the simulation runs are: paddy, other Kharif, sugarcane, wheat and other Rabi. The cropping pattern is described completely in terms of areas under five stipulated crops in each of the two delineated zones.

The simulation runs are conducted for three cropping patterns termed as $A, B$ and $C$ (Table 2).

Table 2: $\quad$ Typical cropping patterns.

\begin{tabular}{|c|c|c|c|c|c|c|}
\hline \multirow{2}{*}{$\begin{array}{c}\text { Cropping } \\
\text { patterns }\end{array}$} & \multirow{2}{*}{ Zone } & \multicolumn{5}{|c|}{ Crop areas(\% of geographical area) } \\
\cline { 3 - 7 } & & $a_{1}$ & $A_{2}$ & $A_{3}$ & $A_{4}$ & $A_{5}$ \\
\hline \multirow{2}{*}{$A$} & 1 & 7.0 & 2.0 & 20.0 & 20.0 & 3.5 \\
& 2 & 7.0 & 2.0 & 20.0 & 20.0 & 3.5 \\
\hline \multirow{2}{*}{$B$} & 1 & 10.4 & 7.1 & 7.8 & 9.2 & 28.6 \\
& 2 & 19.6 & 15.4 & 9.0 & 16.0 & 28.7 \\
\hline \multirow{2}{*}{$C$} & 1 & 11.2 & 0.47 & 2.68 & 2.8 & 28.7 \\
& 2 & 20.1 & 2.5 & 8.1 & 1.7 & 20.6 \\
\hline
\end{tabular}

The crop areas are expressed as fractions of the corresponding geographical areas. Cropping pattern $A$ represents typical current scenario derived from local enquiry. Cropping patterns $B$ and $C$ represent ambitious and conservative patterns, respectively.

\subsection{Convergence to dynamic equilibrium}

As discussed earlier, the groundwater system is deemed to have converged to the state of dynamic equilibrium when the following condition is satisfied. 


$$
\begin{gathered}
\underset{i, k}{\operatorname{Max}}\left|h_{i k}^{(y)}-h_{i k}^{(y-1)}\right|<2 c m \\
\mathrm{i} \in \mathrm{I} \text { and } \mathrm{k} \in \mathrm{K}
\end{gathered}
$$

where, $h_{i k}^{(y)}=$ computed head at $i^{\text {th }}$ node at $k^{\text {th }}$ discrete time during $y^{\text {th }}$ year, $\varepsilon=$ the desired convergence factor, $I=$ set of nodes discretizing the area, and $K=$ set of times discretizing one year.

\subsection{Results}

The simulation model is run over the years until the stipulated convergence criterion is satisfied and the dynamic equilibrium is reached. In the present application the time step is taken as 15 days' As such the dynamic equilibrium is characterized by 24 head fields at first and fifteenth of all months. These head fields are invoked to compute the envisaged state variables. The maximum depth to water table $(D)$ is computed as per equation (Eq. 13). The head fields corresponding to May end (pre monsoon time) and September end (post monsoon time) are employed to compute state variables $q_{\text {pre }}^{Y}, q_{\text {post }}^{Y} q_{\text {pre }}^{H}, q_{\text {post }}^{H}$.

The computed state variables for the three cropping are presented in Table 3 . The computed pre-monsoon depths to water table for the cropping patterns $\mathrm{A}$ and $\mathrm{C}$ are presented in Figure 1. The evolution of the dynamic equilibrium in respect of the cropping pattern $\mathrm{A}$ is illustrated in Figures 2 and 3. Figure 2 reveals that the water table continues to decline as the pumping corresponding to the cropping pattern $\mathrm{A}$ is sustained over the years. However, the water table is associated with a rise of the influent seepage from the two encompassing rivers (Fig. 3). This feed-back mechanism leads to a decline of the fall rate, and hence to the establishment of a dynamic equilibrium after about 66 normal hydrologic years. However, the dynamic equilibrium is characterised by large water table depths especially in the central zone wherein, depths as large as $34 \mathrm{~m}$ are projected. (The depth further increases to $42 \mathrm{~m}$ in case of the cropping pattern B.)

The unconfined aquifer in the study area is known to be about $90 \mathrm{~m}$ thick. Further, there are large numbers of shallow wells extending generally up to a depth of $30 \mathrm{~m}$. As such, this decline may be viewed as severe. Further, the excessive build-up of the influent seepage from the rivers may threaten the

Table 3: $\quad$ Computed state variables.

\begin{tabular}{|c|c|c|c|c|c|}
\hline \multirow{2}{*}{$\begin{array}{c}\text { Cropping } \\
\text { patterns }\end{array}$} & \multicolumn{5}{|c|}{ State variables $[D(\mathrm{~m}) \& \boldsymbol{q}$ (ha-m/day) $]$} \\
\cline { 2 - 6 } & $D$ & $q_{\text {pre }}^{Y}$ & $q_{\text {pre }}^{H}$ & $q_{\text {post }}^{Y}$ & $q_{\text {post }}^{H}$ \\
\hline$A$ & 33.45 & 23.3 & 23.0 & 22.1 & 21.4 \\
\hline$B$ & 41.0 & 45.4 & 47.6 & 43.9 & 46.0 \\
\hline$C$ & 22.7 & 4.3 & 3.6 & 3.3 & 2.4 \\
\hline
\end{tabular}




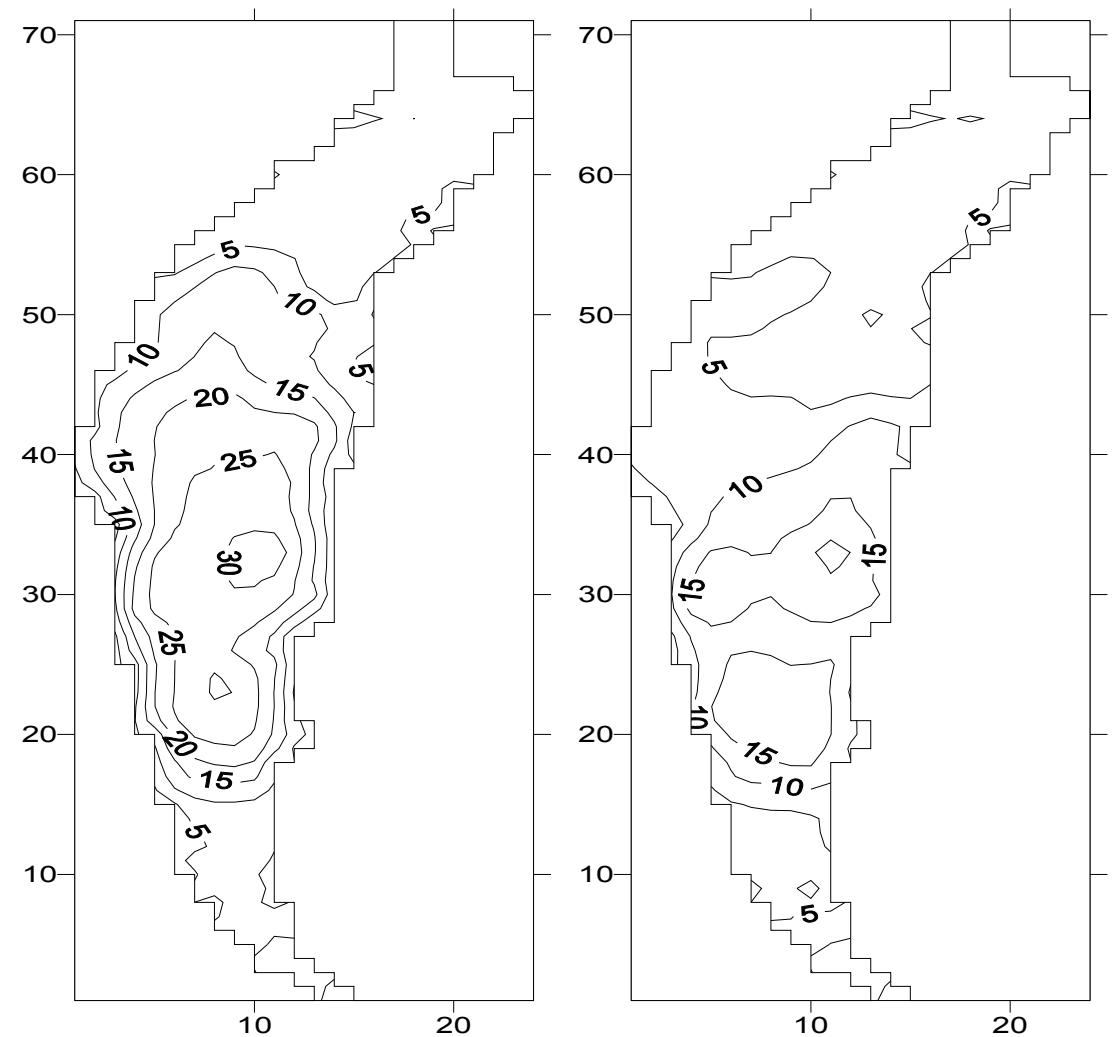

Figure 1: Contours of depth to water table in meters [pre monsoon-cropping patterns A (left) and C (right)].

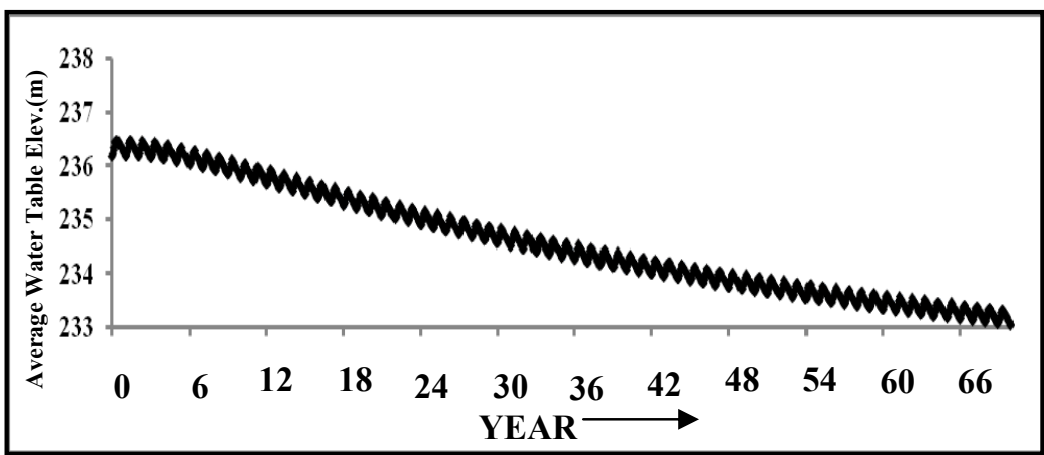

Figure 2: Variation of average water table elevation up to dynamic equilibrium (cropping pattern: $A$ ). 


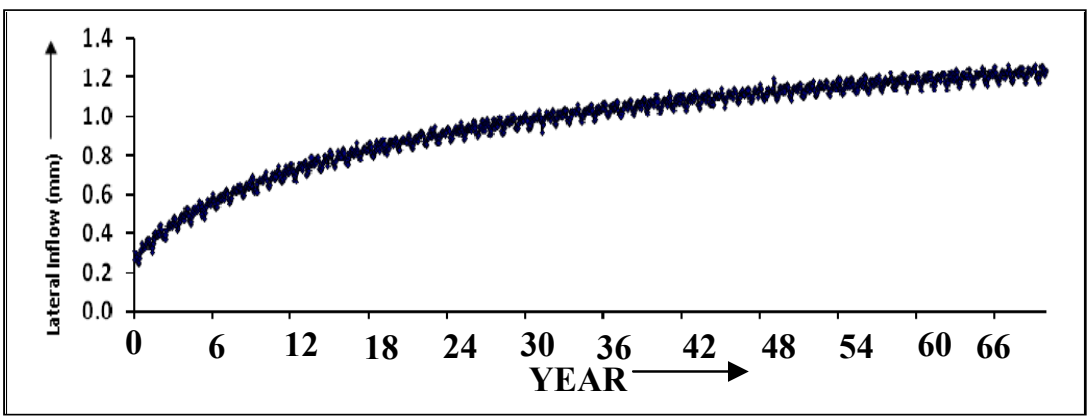

Figure 3: Variation of lateral inflow from Yamuna up to dynamic equilibrium (cropping pattern: $A$ ).

quality of the groundwater, since the quality of water in two rivers is known to be poor. As such, there is a need for attenuating the pumpage and the crop areas. Cropping pattern $\mathrm{C}$ represents a trial set of reduced crop areas. Fig. 1 indicates that implementation of cropping pattern $C$ leads to a significant reduction in the ultimate maximum water table depth. The maximum depth reduces from $34 \mathrm{~m}$ to $23 \mathrm{~m}$, as the cropping pattern is attenuated from A to C. This moderated maximum depth is accompanied by a substantially reduced influent seepage from the two boundary rivers (Table 3 ). As, such the cropping pattern $\mathrm{C}$ may be sustainable over the years, restricting the water table depths as well as the influent seepage.

\section{Conclusion}

The enhanced simulation model presented herein is capable of computing the envisaged state variables (maximum water table depth and critical stream-aquifer flows under dynamic equilibrium) for any given zone-wise cropping pattern. Thus, the model may be employed to arrive at a cropping pattern and the associated pumping pattern, which over the long run, restricts the water table depths and the influent seepage to pre-assigned permissible levels.

\section{References}

[1] Bredehoeft, J.D., and Young, R.A., Conjunctive use of groundwater and surface water for irrigated agriculture: Risk aversion, Water Resources Research, 19: 1111-1121, 1983.

[2] Yu, W., and Haimes, Y.Y., Multilevel optimization for conjunctive use of groundwater and surface water, Water Resources Research, 10(4): 625636, 1974.

[3] Kashyap, D. and Chandra, S., A Distributed Conjunctive Use Model for Optimal Cropping Pattern, IAHS Publ. 135 (Proceedings of the Exeter Symposium July, 1982): 377-384, 1982. 
[4] Gorelick, S.M., A review of distributed parameter groundwater management modeling methods, Water Resources Research, 19(2): 305319, 1983.

[5] Maddock III, T., Algebric technological function from a simulation model, Water Resources Research, 8(1): 129-134, 1972.

[6] Maddock III, T., Nonlinear technological functions for aquifers whose transmissivities vary with drawdown, Water Resources Research, 10(4): 877-881, 1974.

[7] Dreizin, Y.C, Haimes, Y.Y., A hierarchy of response functions for groundwater management, Water Resources Research, 13(1): 78-86, 1977.

[8] Ghosh, S. and Kashyap, D., ANN based model for planning of groundwater development for agricultural usage, Irrigation and Drainage (Wiley) DOI: 10.1002/ird.686: 2012.

[9] Ghosh, S. and Kashyap, D., Kernel Function Model for Planning of Agricultural Groundwater Development, J. Water Resour. Plann. Manage. 138(3): 277-286, 2012.

[10] CBIP (Govt. of India). (1987). "Conjunctive use modeling for ground and surface water in eastern Yamuna canal command area". Project no: $\mathrm{Q}(24) / 83-\mathrm{P}-\mathrm{III}$.

[11] Rathi S., "Numerical modeling of aquifer response in Yamuna-Hindon doab.” M.Tech Dissertation, IIT Roorkee, 1997. 